\title{
Absorptive and Desorptive Capacity Configurations in Supply Chains: An Inverted U-shaped Relationship
}

María Isabel Roldán Bravo ${ }^{a}$, E-mail address: mirbravo@ugr.es;

Mark Stevenson*b, E-mail address: $\underline{\text { m.stevenson@lancaster.ac.uk }}$

Antonia Ruiz Moreno ${ }^{\mathrm{c}}$, E-mail address: aruizmor@ugr.es

Francisco Javier Lloréns Montes ${ }^{\mathrm{c}}$, E-mail address: fllorens @ ugr.es

${ }^{a}$ Department of Business Organization, Faculty of Law and Social Sciences, University of Granada, Campus de Melilla s/n 52005, Melilla, SPAIN. Tel.: (+34) 952698751

${ }^{b}$ Department of Management Science, Lancaster University Management School, Lancaster University, Lancaster, LAI 4YX, Lancashire, UNITED KINGDOM. Tel.: +44 (0)1524 593847

${ }^{c}$ Department of Business Organization, Faculty of Economics and Business Management, University of Granada, Campus de Cartuja s/n 18071, Granada, SPAIN. Tel.: (+34) 958240916; Fax: (+34) 958246222.

*Corresponding author

Funding: This research was supported by MINECO, AGENCIA ESTATAL DE INVESTIGACIÓN and FEDER (EU) under Research Project ECO2017-84138-P and the Regional Government of Andalusia under Research Project P11-SEJ-7294.

Conflicts of Interest: "The authors declare no conflict of interest." 


\title{
Absorptive and Desorptive Capacity Configurations in Supply Chains: An Inverted U-shaped Relationship
}

\begin{abstract}
The extant literature has highlighted the importance of knowledge transfer between a buyer and its supply network for strengthening supply chain competence. This is a bi-directional exchange where the buyer and supply network each act as the sender and receiver of knowledge. Prior research has however largely focused on the knowledge recipient only. We consider both sender and recipient using two key dynamic capabilities related to knowledge transfer: (i) desorptive capacity, which enables the safe transfer of knowledge from the sender; and, (ii) absorptive capacity, which enables the acquisition and assimilation of external knowledge by the recipient. Using the concept of 'fit', we investigate whether organizations strengthen supply chain competence when their desorptive capacity exceeds that of their supply network's (positive misfit) and consider the moderating role of the organization's and supply network's absorptive capacity. Multiple regression analysis of survey data from 250 firms identifies an inverted U-shaped relationship between positive desorptive capacity misfit and supply chain competence. Further, this relationship is shown to be moderated by the supply network's absorptive capacity level. The paper furthers our understanding of supply chain knowledge management enabling buyers and their supply networks to achieve more successful knowledge transfer outcomes.
\end{abstract}

Keywords: Desorptive capacity; absorptive capacity; dynamic capabilities; knowledge management; supply chain; survey. 


\section{Introduction}

For more than a decade, scholars have claimed that competitive advantage can be enhanced by looking beyond the boundaries of the firm - to the capabilities of the supply chain (Ketchen et al. 2014). Yet it remains unclear why some organizations are able to enhance the competitiveness of their supply chains more than others (Chow et al. 2008; Derwik and Hëllstrom, 2017). A growing body of literature has pointed to supply chain knowledge management as the key to strengthening supply chain competence (e.g. Olson, 2018; Pérez Salazar et al., 2018). Indeed, Handoko et al. (2018) recently suggested that enhancing a firm's ability to transfer knowledge to, and leverage knowledge that resides within, its supply network can be of benefit not only to firm performance but also to the effectiveness of the entire supply chain. Thus, organizational capabilities that support the ability to transfer knowledge (Mu et al. 2010) could reinforce an organization's supply chain competence and enhance the supply chain's competitive position (Green et al., 2014).

In general terms, the most basic form of knowledge transfer relies upon a "sender and receiver of knowledge in which knowledge moves from the sender to the receiver" (Whitehead et al. 2016, p.1309). This dyadic concept has been extended to a broader network setting in recent studies, e.g. by Müller-Seitz (2012), Peng et al. (2014), and Roldán Bravo et al. (2016), recognizing that a receiver can be exposed to a variety of senders. It is also important to note that knowledge transfer is bi-directional, with the buyer and supply network taking it in turns to act as sender and recipient. Thus, "knowledge receiving and knowledge sending roles relate to each other and are possibly intertwined" (Szász et al., 2019, p.302).

The extant literature has thus far focused on understanding the characteristics of the knowledge receiver (Easterby-Smith et al. 2008). Amongst these characteristics, absorptive capacity, i.e. an organization's ability to recognize, assimilate, transform, and exploit knowledge (Zahra and George 2002), has received much attention. Studies however have reported contradictory results, while the role of the knowledge sender has been largely neglected (Whitehead et al., 2019) except in a set of papers on desorptive capacity (Vanhaverbeke et al., 2007; Lichtenthaler and Lichtentaler, 2010; Martín de Castro, 2015; Meinlschmidt et al., 2016; Roldán Bravo et al., 2016; Whitehead et al., 2016). Desorptive capacity is concerned with an organization's ability to identify opportunities to exploit its knowledge and transfer it effectively to other network actors (Lichtenthaler and Lichtenthaler, 2009) whilst simultaneously protecting core proprietary knowledge. The concept is thus expected to be a key complement to absorptive capacity in enhancing supply 
chain competence. In fact, it has been argued that both should be considered when evaluating the success of knowledge transfer (Whitehead et al., 2019).

Although prior studies have explicitly distinguished between the roles of being the knowledge sender and receiver, firms can play both roles and be positioned along a continuum from dominant knowledge sender to dominant knowledge receiver (Szász et al., 2019). Along this continuum, the interplay between the receiver's absorptive and sender's desorptive capacity matters; and it is possible to find net sender positions - where sending knowledge outweighs received knowledge - net receiver positions - where received knowledge outweighs sent knowledge - and intermediate positions where firms participate intensively in both activities and where the absorptive and desorptive capacities of each actor play different roles. As a result, these capabilities must first be separated from each other to better understand how they work alone; and then compared to better understand how they work together. To do so, this research proposes that the desorptive capacity of each actor involved in knowledge transfer should be considered simultaneously, placing the concept of desorptive capacity fit - referring to the (mis)match between the level of desorptive capacity that an organization perceives from its supply network and the organization's own level of desorptive capacity - along a continuum from one extreme misfit position to the other via more aligned positions.

From the above it follows that when the desorptive capacity of the firm and its supply network are not aligned, there is a misfit. More specifically, when an organization's own level of desorptive capacity exceeds that of its supply network there is a positive misfit; and when the desorptive capacity of the supply network exceeds that of the organization there is a negative misfit. We theorize on whether organizations are better able to manage their supply chains when their level of desorptive capacity exceeds that of their supply network's (positive misfit). Given that moving towards a more intensive knowledge-sending role demands investing in additional desorptive capacity, which will be costly to an organization, we seek to address the following question:

To what extent should the desorptive capacity of an organization be aligned with that of the supply network? In other words, should organizations have the same, more or less desorptive capacity than their supply network?

We will later hypothesize that the relationship between positive desorptive capacity misfit and supply chain competence follows an inverted U-shaped function. In other words, despite the benefits of an organization's desorptive capacity, an excessive level of positive desorptive 
capacity misfit could be detrimental to supply chain competence since it could potentially enable opportunistic behavior within the supply network. Meanwhile, we will also argue that supply chain competence is enhanced at low to moderate levels of positive desorptive capacity misfit.

To gain a better understanding of the relationship between positive desorptive capacity misfit and supply chain competence, and to provide a second contribution from our study, we will also consider the potential moderating effect of absorptive capacity. Sikimic et al. (2016) demonstrated that there are synergies between desorptive and absorptive capacities thereby supporting earlier anecdotal evidence from practice and theoretical development (Lichtenthaler and Lichtenthaler, 2009). Following this, we will analyze the synergistic effect of the organization's and supply network's absorptive capacity on positive desorptive capacity misfit based on their potential complementarity. Given increasing interest in understanding the interplay between the sender's desorptive capacity and receiver's absorptive capacity (Szász et al., 2019) to determine the effectiveness of knowledge transfer, we include this in the form of a post-hoc analysis.

Overall, the study aims to: (1) investigate the effect of positive desorptive capacity misfit on supply chain competence; (2) analyze the moderating effect of an organization's absorptive capacity on the relationship between desorptive capacity misfit and supply chain competence; and, (3) explore the moderating effect of a supply network's absorptive capacity on the aforementioned relationship. The hypotheses we later present will be tested by applying multiple regression analysis to survey data collected from a sample of 250 firms.

The remainder of this paper is organized as follows. Section 2 reviews related research on knowledge management capabilities and supply chain competence before describing the model and hypotheses for analysis. Section 3 outlines the research method adopted before Section 4 presents the empirical results. Section 5 then provides a discussion of the findings followed by Section 6 where the paper concludes.

\section{Theoretical Development}

This study is grounded in the theory of dynamic capabilities, which can be defined as "a firm's behavioral orientation to constantly integrate, reconfigure, renew and recreate its resources and capabilities and, most importantly, upgrade and reconstruct its core capabilities in response to the changing environment to attain and sustain competitive advantage" (Wang and Ahmed 2007, p.35). These capabilities are derived from, among other sources, knowledge exchange between supply chain partners (Handfield et al., 2015). Two dynamic 
capabilities in particular can be identified from the literature on knowledge transfer: desorptive capacity, i.e. the capability that makes the safe transfer of knowledge possible; and absorptive capacity, i.e. the inverse of desorptive capacity that allows external knowledge to be acquired and used effectively. The levels of desorptive and absorptive capacity are not uniform but greater or lesser depending on the relationship that an organization maintains with possible knowledge sources (Teece et al., 1997) - in our case, each of the partners in its supply network (Dyer and Singh, 1998; Wagner, 2012). This reflects the fact that firms often look externally to their supply network for additional sources of capabilities to enhance the performance of their existing internal capabilities (Malhotra and Mackelprang, 2012).

Following the above line of reasoning, we propose a model to explore the effect of the alignment between an organization's desorptive capacity and that of its supply network on supply chain competence and consider the moderating role of both the organization's and supply network's absorptive capacity.

\subsection{Desorptive Capacity in a Supply Chain Context}

Desorptive capacity as a dynamic capability is composed of "sensing", "seizing" and "transforming" capabilities (Teece, 2007) and has been defined as "the firm's ability to externally exploit knowledge" (Lichtenthaler and Lichtenthaler, 2009, p.1322). There are two key phases to desorptive capacity: (i) the identification of knowledge transfer opportunities whilst protecting core proprietary knowledge; and, (ii) the transfer of knowledge and the facilitation of its application by knowledge recipients (Ziegler et al. 2013). Desorptive capacity has even been categorized as "the facilitator of knowledge transfer" (Dezi et al. 2018, p.33) but it is in fact a broader concept that also encompasses disseminative capabilities. This concept - disseminative capability - has been related to the effectiveness and efficiency of knowledge transfer, which might be perceived as contradictory to the protection of knowledge. It is however argued that both effective knowledge transfer and effective knowledge protection are possible under the umbrella of desorptive capacity. Meanwhile, the importance of both activities was highlighted by Yang et al. (2014).

Desorptive capacity has been linked to supply chain management. For instance, Meinlschmidt et al. (2016) provided evidence in support of the positive effects of desorptive capacity on the development of supply chain capabilities. The authors demonstrated that organizations with higher levels of desorptive capacity were able to recognize sustainable knowledge transfer opportunities, to identify the suppliers that needed the information, and to transfer it whilst also facilitating its application. Further, there is empirical evidence of the 
reinforcing effect that ambidexterity has on the benefits of desorptive capacity in a supply chain context (Roldán Bravo et al., 2018). Although Roldán Bravo et al. (2018) provided empirical evidence for the impact of an organization's desorptive capacity on its supply chain competence, the capabilities of its trading partners - i.e. the desorptive capacity of the suppliers in its network - can also influence organizational performance (Richey et al., 2007) as firms do not operate in isolation. In fact, when buying firms source from suppliers, it is not their internal capabilities alone but rather the collective capabilities of their supply chains that determine overall supply chain performance (Pulles et al., 2014).

As a result, the internal desorptive capacity possessed by an organization and the external desorptive capacity possessed by the members of its supply network jointly determine the extent to which superior organizational performance can be created and the position along the continuum from dominant knowledge-receiver to dominant knowledge-sender. To fully capture the role played by the buying organization in the abovementioned continuum, we explore the concept of desorptive capacity misfit from a supply chain perspective.

\subsection{Linking Positive Desorptive Capacity Misfit to Supply Chain Competence}

When considering multi-directional knowledge transfer between an organization and its supply network, it is important to follow a transparent and reciprocal approach. Along these lines, Hosseini et al. (2017) asserted that boundary spanning capabilities - such as desorptive capacity - allow firms to retain and transfer information, reducing the cognitive distance between partners and, as a result, reinforcing mutual understanding. Therefore, the organization and its network members should take it in turns to be the knowledge source (or sender) and recipient. In other words, they should participate intensively in both knowledgesending and receiving roles (Szász et al., 2019).

Previous studies have recognized that a certain degree of overlap between the capabilities and resources of actors can be beneficial for learning purposes (Mowery et al. 1996; Lane and Lubatkin 1998; Mowery et al. 1998; Luo and Deng 2009). In our case, when internal and external desorptive capacity are jointly considered, synergies may exist at least in part due to an alignment between the desorptive capacities of the firm and its supply network members. Yet a buying firm's rivals may also source from the same suppliers, and thus they may be more able to benefit from the collective capabilities of their supply chains (Pulles et al., 2014). In such a scenario, if an organization aspires to become a dominant player, then meeting at least a minimum desorptive capacity threshold level relative to its supply network 
members is necessary ( $\mathrm{D}^{\prime}$ Souza and Kulkarni 2015). This also prevents an organization from suffering from knowledge leakage to competitors.

In an automotive industry case study presented by Takeishi (2002), some automakers suffered from knowledge diffusion to competitors via shared suppliers. For example, there was an intentional technological and managerial knowledge transfer by suppliers from one automaker to another. Meanwhile, rival automakers made a deliberate attempt to learn about the engineering expertise of their rivals through their suppliers. It therefore becomes important to strike a balance and avoid suppliers being reluctant to share knowledge with the buyer whilst discouraging information leakage from the supplier to the buyer's competitors. Some firms are better able to achieve this than others. For example, it was found that General Motors experienced a lack of knowledge transfer from its suppliers because of perceived aggressive supply chain practices whilst, at the same time, Ford and Chrysler benefited from the resources and capabilities of shared suppliers (Terpend and Ashenbaum, 2012).

Based on the above, having a greater level of desorptive capacity than other members of the supply network, i.e. positive desorptive capacity misfit, is argued to be beneficial to an organization. We further propose that an organization that has superior teaching capabilities can position the firm as a key player in the supply chain, translating its knowledge transfer efforts into greater supply chain competence. The importance of enhancing this competence increases if we consider that each organization's supply chain competence strengthens the entire supply chain's competitive position. Supply chain competence was defined by Chow et al. (2008, p.667) as "a portfolio of organizational, managerial, technical and strategic capabilities and skills developed by enterprises over time" composed of quality, service, operations and distribution issues. Meanwhile, the top 25 companies that rated their competence in managing the supply chain as excellent in the annual research report of AMR Research/Gartner achieved better financial performance than their competitors (Derwik and Hellström, 2017).

Given these arguments, it is plausible that organizations with a desorptive capacity level that exceeds that of their supply network possess greater supply chain competence than organizations that develop a similar or lower level of desorptive capacity. In other words, becoming a more intensive knowledge-sender benefits an organization's supply chain competence.

The above positive effects may however decline and even become negative if the excess desorptive capacity developed by an organization compared to its supply network is too severe. As a result, under excessive positive desorptive capacity misfit, the knowledge 
transfer process from the members of the supply network to the organization may not work effectively, which could have serious consequences, such as a lack of understanding of current supply chain needs or a loss of abilities related to supply chain management. Under such circumstances, an asymmetrical knowledge transfer is unlikely to lead to successful reciprocal learning, which in turn would be detrimental to a firm's competitive advantage (Argote and Darr, 2000). Overall, although a positive desorptive capacity misfit is expected to increase an organization's supply chain competence, beyond a certain point the effect may change and result in lower supply chain competence. Thus, we propose verifying the following hypothesis:

H1. Positive desorptive capacity misfit has an inverted U-shaped relationship with supply chain competence.

\subsection{Absorptive Capacity within the Supply Chain Context}

The importance of absorptive capacity within the context of supply chains (Azadegan, 2011; Sáenz et al., 2014) is justified by an organization's need to adapt supply to meet demand, acquiring external knowledge, particularly about the preferences of end-users or customers (Barney, 2012; Sáenz et al., 2014). With respect to suppliers' absorptive capacity, Revilla et al. (2013) demonstrated that the higher the level, the greater the likelihood of using the buyer's knowledge to enhance internal competences and capabilities, thereby improving performance.

A clear prerequisite for absorptive capacity is the permeability of the buyer's and suppliers' boundaries (Volberda et al., 2010). Absorptive capacity has been described as the fuel for inter-organizational learning and capacity dynamics (Cheng and Lu, 2017); and it has been advocated as both the route to achieving operational performance (Patel et al., 2012) and to predicting supply chain resilience (Cheng and $\mathrm{Lu}, 2017$ ). Recent literature has begun to analyze the influence of this capability on specific aspects of performance, e.g. cost reduction, quality, reliability, etc., although more research is needed (Sáenz et al., 2014). To fill this gap, we examine the interplay between the buyer's and supply network's absorptive capacity on the abovementioned relationship.

\subsubsection{The Moderating Role of the Buyer's Absorptive Capacity}

The literature has identified the importance of the recipient's absorptive capacity for successful knowledge transfer (Cohen and Levinthal, 1990; Mowery et al., 1996, 1998; Dyer and Singh, 1998; Lane and Lubatkin, 1998; Schulze et al., 2014). More specifically, the lack 
of a sufficient level of absorptive capacity impedes an organization's ability to recognize the value of new knowledge, assimilate it and apply it successfully either to commercial ends (Moedas and Jouini, 2008) or within its own processes and routines (Lane and Lubatkin, 1998). In a supply chain context, Azadegan (2011) identified the buyer's absorptive capacity as a catalyst for the effective exploitation of supplier knowledge as it facilitates an understanding and assimilation of their knowledge. This capacity has been related to a greater chance of obtaining cost reductions and spillover benefits from collaborative initiatives (Cao and Zhang, 2011), the more efficient use of resources, and improvements in quality and reliability in buyer-supplier research (Sáenz et al., 2014). This is because the acquisition, assimilation and exploitation of knowledge allows a buying organization to simultaneously prevent stock-outs whilst achieving low inventory levels that reduce costs and rapidly deliver products and services in response to demand, thereby reinforcing the organization's supply chain competence.

Literature on open innovation suggests the existence of synergies between the development of desorptive and absorptive capacities (Lichtenthaler and Lichtenthaler, 2009; Sikimic et al., 2016). This assertion is based on the theory of complementarity, which proposes that the real value of capabilities stems from the way in which they are combined or interact (Cassiman and Veugelers, 2006). The theoretical framework proposed by Lichtenthaler and Lichtenthaler (2009) presented absorptive and desorptive capacity as two pieces of a puzzle that go together. Likewise, Sikimic et al. (2016) illustrated the case of Lucent where the co-development and reinforcement of absorptive and desorptive capacities took place through the practice of bidirectional technology transfer. As such, greater absorptive capacity by an organization regarding its supply network will enhance its desorptive capacity as "those who understand, teach" (Schulze et al. 2014, p.79) and the combination of both capabilities may translate into greater performance gains.

If absorptive and desorptive capacities are key to an organization enhancing its supply chain competence, then the organization must also consider how the supply network's capacities interact with its own. If suppliers underperform on their teaching capabilities, then the buyer would be encouraged to increase its relative absorptive capacity and counteract potential disadvantages from positive desorptive capacity misfit. In addition, a lack of absorptive capacity has been predicated as a moderator of the source's ability to share information on knowledge transfer outcomes (Gupta and Govindarajan, 2000; Chang et al., 2012). This amplifies the positive impact on supply chain competence of low to medium levels of positive desorptive capacity misfit for firms developing greater absorptive capacity 
than it does for firms lesser developing absorptive capacity. As a result, by compensating for positive desorptive capacity misfit, a buyer's absorptive capacity postpones the point at which the organization starts to lose its competitive advantage. Hence, a buyer's absorptive capacity may weaken the negative effect of greater positive desorptive capacity misfit on supply chain competence. Thus, the right-hand tail of the inverted U-shaped relationship becomes flatter, and the inflection point turning towards the downward trend may only emerge later on. Therefore, we propose verifying the following hypothesis:

H2. The buyer firm's absorptive capacity negatively moderates the inverted U-shaped relationship between positive desorptive capacity misfit and supply chain competence.

\subsubsection{The Moderating Role of the Supply Network's Absorptive Capacity}

When the buyer acts as a source of knowledge, it should appraise its supply network's relative absorptive capacity in order to adapt its own knowledge transfer activities (Schulze et al., 2014). In our case, positive desorptive capacity misfit in a multi-directional knowledge transfer context is not as important when the recipient's absorptive capacity is high compared to when the recipient's absorptive capacity is lower. Thus, the buyer firm's desorptive capacity can enable the internalization of external knowledge (Huang and Rice, 2009; Lichtenthaler and Lichtenthaler, 2009; Spithoven et al., 2010) if absorptive capacity is not sufficiently developed by other members of the supply network. In other words, the marginal effect of the buyer's desorptive capacity decreases as the supply network's absorptive capacity increases (Peng et al., 2014). As synergistic combinations of supply chain members' capabilities could lead to greater organizational performance, the buyer firm will obtain greater benefits when relating to suppliers that it perceives to have complementary levels of desorptive or absorptive capacity to its own (Dyer and Singh, 1998).

For the case that the supply network develops greater levels of absorptive capacity and positive desorptive capacity misfit is high, it may be difficult to enhance the buyer's supply chain competence by increasing positive desorptive capacity misfit. In such a scenario, the possibility of learning is not assured and the buyer is more exposed to a loss of competitive advantage. A failure to transfer knowledge from the buyer to another member of the network is most likely to occur when the potential receiver is known to play a prominent role in the market, which could lead to a loss of competitive advantage for the sender (Lichtenthaler and Lichtenthaler, 2010). In other words, a situation in which the supply network seeks to absorb the knowledge of the buyer without reciprocating that knowledge can be spread to several other network ties. This suggests that the supply network's absorptive capacity, in turn, 
diminishes the positive relationship between positive desorptive capacity misfit and supply chain competence at low to medium levels of misfit and expedites the point at which the organization starts to lose its competitive advantage. Hence, the supply network's absorptive capacity may increase the negative effect of positive desorptive capacity misfit on supply chain competence (within dominant buyer knowledge-sending roles). As such, the right-hand tail of the inverted U-shaped relationship becomes sharper, and the inflection point turning toward the downward trend may start to emerge earlier. Thus, we propose verifying the following hypothesis:

H3. The supply network's absorptive capacity positively moderates the inverted U-shaped relationship between positive desorptive capacity misfit and supply chain competence.

Figure 1 summarizes our research model and the three hypotheses, which will be tested by following the method outlined in the next section of this paper.

\section{[Take in Figure 1]}

\section{Method}

\subsection{Sample and Procedures}

We sourced the data via a survey from the population of Spanish manufacturing and service firms in the Iberian balance sheet analysis system (SABI) database. In the first step, we classified companies into industrial sectors according to the CNAE (Classification of Economic Activities) catalogue, excluding those that were not located in the middle of the supply chain. In next step, we conducted a random sample of 2,000 firms and applied a CATI survey method. In this type of data gathering approach, a computer system randomly shows potential respondents' contact details to the interviewers. Through this system, it is possible to schedule and reschedule telephone interview times with interviewees and save the questionnaire in real time. Five interviewers specifically trained for this research performed the data gathering. Respondents were given written definitions of the main concepts in advance together with the contact details of one of the researchers in case of doubts or suggestions. All five interviewers worked simultaneously for 8 hours a day throughout the fieldwork period with responses collected over a five-month period.

In all valid cases, the informants were in a position related to operations or supply chain management. The survey was pretested by selected supply chain managers and operations management academics, which enabled us to avoid content ambiguities and mistakes. Thus, 
the content validity of the scales is considered adequate. We received 252 responses after two rounds of data collection. After removing incomplete questionnaires, we obtained 250 valid questionnaires, a final response rate of $12.5 \%$. Table 1 reveals the demographic details of the sample.

\section{[Take in Table 1]}

The potential for non-response bias was analyzed following the procedure suggested by Armstrong and Overton (1997) where later respondents are considered those most similar to non-respondents. Thus, we conducted a t-test to evaluate the difference between early (150 respondents) and late respondents (100 respondents) with regards to the key variables used in this study. The t-test results led us to affirm the absence of non-response bias in the final results of the study $(\mathrm{p}=0.05)$.

\subsection{Measures}

A seven-point scale was used for the measures, which were taken from the literature and therefore previously established and tested. Appendix 1 shows all measurement scales and items. We adapted the scale for supply chain competence from Chow et al. (2008), the scales for absorptive capacity from Wagner (2012), and the scales for desorptive capacity from Roldán Bravo et al. (2016). The supply network's absorptive capacity was measured by adapting the four-item scale validated by Wagner (2012) to evaluate the focal firm's perception of its supply network's capacity.

The positive desorptive capacity misfit measure was obtained from the difference between the evaluations of the firm's desorptive capacity relative to its evaluation of the supply network's desorptive capacity. As a positive misfit corresponds to the proactive development of the firm's desorptive capacity relative to the supply network, we had to homogenize the data following the procedure described in Ruiz Moreno et al. (2016). For the statistical analysis, once the difference was obtained the point values were transformed into positive values ranging from 1 to 13 . The values refer to the difference between the perceived organization's supply network desorptive capacity and the organization's desorptive capacity (from 13 to 1 ), with 13 reflecting the highest magnitude of desorptive capacity misfit and 1 the lowest.

Four control variables were considered in this study. First, we analyzed size based on the number of employees to reflect a firm's ability to commit resources (Moorman and Slotegraaf, 1999). Second, we considered the influence of the sector on supply chain 
management (Wu et al., 2014), which was considered in terms of manufacturing or service sector. Third, the number of suppliers in an organization's supply network was included as this can influence a supplier's response capacity and thus the buyer itself. It can also affect the coordination needed to achieve efficiency and the results of supply chain innovation (Choi and Krause, 2006). Finally, we controlled for firm age in terms of the number of years since the firm was founded as this can influence management practices and profitability (White et al., 1999). We used logarithmic transformations for firm age, employees, and number of suppliers, a commonly used approach in research.

\section{Analysis and Results}

\subsection{Construct and Indicator Reliability}

To perform the reliability analysis (Fornell and Larcker, 1981), we estimated the composite reliability (CR) and corrected item-total-correlation (CITC). Table 2 presents the final standardised factor loadings, CR, Average Variance Extracted (AVE) and CITC values for all scale variables. Factor loadings of less than 0.5 (Hair et al., 2010) were deleted (SCC7, AC1 and AC5). The remaining item loadings were higher than the recommended value, suggesting acceptable indicator reliability (Table 2). All CR values exceeded the recommended value of 0.7 (Fornell and Larcker, 1981), suggesting appropriate psychometric characteristics. As shown in Table 2, CITC values are acceptable as they are higher than 0.3 (Nunally and Bernstein, 1994). Altogether, we confirmed the internal reliability of all of the scales and established the absence of construct reliability concerns for the measurement model.

\section{[Take in Table 2]}

\subsection{Scale Validation: Convergent and Discriminant Validity}

We performed a confirmatory factor analysis to validate the measures for all of the variables. The overall indices suggested acceptable fit: normed chi-square $\left(\chi^{2} / \mathrm{df}=2.37\right), \mathrm{RMSEA}=0.07$, $\mathrm{NFI}=0.83, \mathrm{NNFI}=0.88$, and $\mathrm{CFI}=0.9$. All item loadings were significant and above 0.5 and the average variance extracted (AVE) was greater than 0.5 (Table 2). More specifically, supply chain competence: 0.5943 , a firm's absorptive capacity: 0.7021 , the supply network's absorptive capacity: 0.7246 , a firm's desorptive capacity: 0.7909 , and the supply network's desorptive capacity: 0.7167 were all greater than the recommended minimum. Further, composite reliability was greater than 0.7 . Thus, convergent validity was confirmed. The squared root of the AVE for each construct is greater than any correlation. Therefore, there is 
evidence for discriminant validity. Finally, Table 3 presents the means, standard deviations and correlations. Note that the correlations are all below the marginal threshold of 0.65 .

[Take in Table 3]

\subsection{Common Method Variance}

We performed methodological tests, starting with Harman's single-factor test (Podsakoff et al., 2003). We loaded all variables in the exploratory factor analysis, constraining the number of factors to 1 . As the first component accounts for less than 50 percent of all variables, common method variance is not a serious problem in our sample. As an alternative test, Chang et al. (2010) suggested using confirmatory factor analysis (CFA). Following their suggestions, we constrained all items to load only one factor in the CFA. As the statistics $\left(\mathrm{RMSEA}=0.176, \mathrm{NFI}=0.622, \mathrm{CFI}=0.649, \mathrm{IFI}=0.65\right.$, normed $\left.\chi^{2}=8.69\right)$ did not show good fit, we were able to conclude that a single factor does not account for all of the variance in the data.

\subsection{Detection of Misspecifications}

We investigated if misspecifications were present in our model by examining both modification indices, expected parameter changes and the power of modification indices (Saris et al., 2009; Shashi et al., 2019). The analysis of the modification indices and the expected parameter changes suggested including a correlated error between SCC9 and SCC8. As theoretical issues also supported this inclusion, this change was included in the model. Consequently, the parameter estimation is 0.451 for the correlated error. Additional analysis suggested further changes were not necessary. The fit indices of the final measurement model are: Chi-square/Df=2.19, RMSEA=0.069, NFI=0.846, NNFI=0.894, and CFI=0.91.

\subsection{Hypothesis Testing}

Multiple regression analysis was used to test the hypotheses. Table 4 shows the results of an analysis of nine models. Model 1 includes control variables only. In Model 2 we added the independent variable, positive desorptive capacity misfit, which positively and significantly affects supply chain competence $(0.234, \mathrm{p}<0.001)$. In Model 3 , we regressed the squared term of positive desorptive capacity misfit on supply chain competence. Table 4 shows that the curvilinear relationship was statistically significant $(\beta=-0.151 ; \mathrm{p}<0.05)$. There is also an increasing amount of $\mathrm{R}^{2}$ from Model 2 to Model $3(0.085, \mathrm{p}<0.05)$. The relationship between positive desorptive capacity misfit and supply chain competence showed an upward trend at lower levels of positive desorptive capacity misfit and a downward trend at higher levels of 
positive desorptive capacity misfit. As depicted in Figure 2, the shape of the relationship is consistent with Hypothesis 1, which proposed an inverted U-shaped relationship between positive desorptive capacity misfit and supply chain competence. Thus, it can be concluded that $\mathrm{H} 1$ is supported by the data. We calculated the inflection point following Aiken and West's (1991) approach, and found that the inflection point of positive desorptive capacity misfit was at 1.2738. When the mean centered positive desorptive capacity misfit is lower than 1.2738 (between an interval from -3 to 3 ) the trend of the relationship with supply chain competence is upward. When positive desorptive capacity misfit is larger than 1.2738 , the trend turns downward.

[Take in Table 4 and Figure 2]

Models 4 and 5 included the isolated effect of the moderating variables, i.e. the firm's absorptive capacity and the supply network's absorptive capacity. Models 6 and 7 tested the moderating effect of a firm's absorptive capacity and supply network's absorptive capacity. The results of the moderating effect were statistically significant for the firm's absorptive capacity $(-0.145, \mathrm{p}<0.05)$ but not significant for the supply network's absorptive capacity. Models 8 and 9 tested the moderating effect of the firm's absorptive capacity and the supply network's absorptive capacity on the previous hypothesized relationship. To test these effects we introduced the product terms between the moderating variables and squared positive desorptive capacity misfit. The results of the moderating effect were only significant in Model 9, which means Hypothesis 2 is not supported by the data.

To show the pattern of the interaction effect, we plotted the simple main effects in Figure 3 according to Cohen et al.'s (2003) procedure. Figure 3 shows that the point of inflection in the inverted U-shaped relationship between positive desorptive capacity misfit and supply chain competence shifted horizontally as a function of the supply network's absorptive capacity. As a result, the supply network's absorptive capacity increases the negative effect of positive desorptive capacity misfit on supply chain competence when the supply network's absorptive capacity is high. Since the inverted U-shaped relationship between positive desorptive capacity misfit and supply chain competence is weaker for organizations with supply network members that have a higher absorptive capacity, Hypothesis 3 is supported. 


\subsection{Post-hoc Analysis}

In this subsection, we investigate how the interplay between the desorptive capacity of the knowledge source and the absorptive capacity of the knowledge recipient (Whitehead et al., 2019) impacts the effectiveness of knowledge transfer activities in enhancing supply chain competence. We focus on the buyer as the knowledge source in terms of their desorptive capacity and the supply network as the knowledge recipient in terms of its absorptive capacity. Specifically, we compare the level of alignment between the two and analyze the influence on supply chain competence of a continuum from predominant supply network's absorptive capacity to predominant firm's desorptive capacity via possible intermediate points. A priori, one can expect that the greater the level of desorptive capacity that an organization develops relative to its supply network's absorptive capacity, the greater the supply chain competence will be as it enables and supports the partner firm's absorptive capacity (Lichtenthaler and Lichtenthaler, 2010; Roldán Bravo et al., 2016; Whitehead et al., 2019). However, the absence of the receiver's absorptive capacity - in our case, the supply network's ability to identify the value of new knowledge, assimilate and apply it - inhibits the potential benefits of a firm's desorptive capacity. Taken together, positive desorptiveabsorptive capacity misfit, where a firm's desorptive capacity outweighs the supply network's absorptive capacity, is expected to benefit an organization's supply chain competence while excessive misfit is anticipated to be detrimental. Therefore, we expect a curvilinear relationship between positive desorptive-absorptive capacity misfit and supply chain competence.

The regression results in Table 5 support this conclusion $(\beta=-0.151 ; \mathrm{p}<0.05)$. Thus, the relationship between positive desorptive-absorptive capacity misfit and supply chain competence showed an upward trend at lower levels of positive desorptive-absorptive capacity misfit and a downward trend at higher levels. This analysis confirms Whitehead et al. (2019, p.287), i.e. that "both capabilities are necessary but alone are insufficient to support successful supply chain collaborative engagement”.

[Take in Table 5]

\section{Discussion}

First, our findings show that, in contrast to previous literature that linked a knowledge source's desorptive capacity to supply chain management (Meinlschmidt et al., 2016; Roldán Bravo et al., 2016, 2018; Whitehead et al., 2016), the desorptive capacity of each actor 
involved in knowledge transfer should be considered simultaneously as firms can take on various roles within supply chain knowledge transfer. As was hypothesized in H1, we provide empirical evidence on the influence of asymmetrical desorptive capacity on supply chain competence and the nonlinear relationship between these variables. We recognize that differences between supply chain partners are unavoidable (Nyaga et al., 2013) and there could potentially be understandable reasons why most advanced companies learn less than their partners. In fact, our results show that symmetrical levels of desorptive capacity are not the optimum solution in supply chain competence terms. In contrast, our results suggest that the appropriate level of asymmetry in knowledge transfer depends on the level of positive desorptive capacity misfit. Our findings are in line with Braun et al. (2012) in that they confirm that all parties require substantial desorptive capacities if they are to mutually benefit from knowledge transfer, also offering empirical support to Soda and Furlotti (2017) who argued that there are benefits from having a certain degree of overlap in capabilities. In addition, this result is instructive given the rise in importance of desorptive capacity for business purposes thereby expanding current understanding of the value of relational asymmetry for supply chain competitive advantage.

Second, with regards to H2, i.e. testing the moderating effect of an organization's absorptive capacity, we did not find statistically significant evidence that under conditions of greater levels of firm absorptive capacity, the curvilinear effect that positive desorptive capacity misfit has on supply chain competence is reduced. Despite not finding statistically significant support for $\mathrm{H} 2$, the obtained result was at least in the hypothesized direction, supporting the assumption of Ishihara and Zolkiewski (2017) that absorptive capacity may lack value for the receiver of knowledge when the sender's disseminative capacity is low.

Third, with regards to $\mathrm{H} 3$, our findings provide support for the positive moderation effect of the supply network's absorptive capacity on the inverted U-shaped relationship between positive desorptive capacity misfit and supply chain competence. This result advances the assertion in Roldán Bravo et al. (2016) that high levels of supply network absorptive capacity can lead to the hazard of opportunistic behavior from an organization's supply network if this does not go hand-in-hand with high levels of desorptive capacity in the supply network. Our findings extend this as it was found that the supply network's absorptive capacity can damage supply chain competence if the desorptive capacities of the organization and its supply network are too asymmetrical. In other words, if the organization is placed at the extreme of the continuum as a dominant knowledge sender, greater levels of supply network absorptive capacity may put the firm at a disadvantage. Therefore, a great disequilibrium among their 
desorptive capabilities added to greater levels of supply network absorptive capacity may lead to undesirable behavior from the supply network.

Fourth, and in contrast to Whitehead et al. (2016), our post-hoc analysis showed that certain levels of asymmetry/imbalance between a firm's desorptive capacity and the supply network's absorptive capacity seem to be beneficial for supply chain competence. A possible explanation for this is that we focused on a firm's desorptive capacity while Whitehead et al. (2016) focused on distributive capability. Nonetheless, our results show that excessive asymmetry is detrimental as both capabilities are essential for benefitting from knowledge transfer. As argued by the aforementioned study, asymmetry between the source and recipient of knowledge capabilities is possible and performing behavioral changes to increase the success of knowledge transfer is needed. In our case, when asymmetry is too big, i.e. the firm's desorptive capacity greatly exceeds the supply network's absorptive capacity, then the supply network must develop its absorptive capacity to benefit from knowledge transfer as a low-performing receiver cannot catch the signal sent by a high-performing sender (Ishihara and Zolkiewski, 2017).

\section{Implications and Concluding Remarks}

Firms can be positioned along a continuum from dominant knowledge sender to dominant knowledge receiver (Szász et al., 2019). In this paper, it has been proposed that the desorptive capacity of each actor involved in knowledge transfer should be considered simultaneously, placing the concept of desorptive capacity fit on a continuum between the two misfit extremes via more aligned positions. We began by asking: To what extent should the desorptive capacity of an organization be aligned with that of the supply network? The empirical evidence revealed that moderate levels of positive desorptive capacity misfit are the best alternative for an organization to enhance its supply chain competence. We also considered the potential moderating effect of organizational and supply network absorptive capacity on the U-shaped relationship between positive desorptive capacity misfit and supply chain competence. Although we did not find statistically significant evidence for organizational absorptive capacity, the supply network's absorptive capacity did moderate the U-shaped relationship.

The paper now closes with the theoretical and practical implications followed by the limitations and future research directions. 


\subsection{Theoretical Implications}

The findings of our study make several meaningful contributions to the body of knowledge. First, we contribute to literature investigating which knowledge capabilities organizations should develop (Hosseini et al., 2017) in order to add value to, and extract value from, their supply chains (Pulles et al., 2014). In doing so, we apply the concept of fit to a specific capability in the dynamic capability framework, i.e. desorptive capacity. Although earlier studies have started to analyze the influence of this variable, we introduce the impact of the desorptive capacity asymmetry/symmetry of all possible knowledge sources involved in knowledge transfer. In this regard, we conceptualized fit in terms of matching, going beyond an 'all or nothing' association between an organization's level of desorptive capacity and the supply network's desorptive capacity. Thus, we introduce an alignment perspective to a complex supply chain phenomenon.

Second, we provide greater understanding of how desorptive capacity can provide competitive advantage to a supply chain. Prior empirical research focuses on linear relationships between variables. Consequently, the non-linear path of exploring symmetry/asymmetry amongst the desorptive capabilities of all possible knowledge sources has been overlooked. By investigating the curvilinear effect of positive desorptive capacity misfit on supply chain competence, our study contributes to this research stream and sheds light on the importance of considering asymmetry when analyzing the supply chain knowledge transfer process.

Third, collectively analyzing the effect of the moderating variables in our study confirms the view of Lichtenthaler and Lichtenthaler (2010) where the development of internal absorptive capacity can be used to compensate for lower levels of external capabilities and vice versa, as synergies are present between both capacities. Furthermore, our study expands current understanding of absorptive capacity as a necessary but insufficient dynamic capability to achieve effective knowledge transfer. In addition, it provides a new perspective to analyzing the source and recipient of knowledge capabilities as it takes into account the risk of greater levels of supply network absorptive capacity under positive desorptive capacity misfit. This finding provides researchers with additional insight into the complexities of supply chain knowledge management and deepens current understanding of the hazards that a buyer organization may suffer from when it transfers knowledge to a supply network that learns without reciprocating.

Finally, the post-hoc analysis responds to calls in the literature (Denford and Ferris, 2018; Szász et al., 2019; Whitehead et al., 2019) and expands understanding of the pertinence of 
symmetry/asymmetry between the capabilities of the knowledge source and recipient in the supply chain knowledge transfer process.

\subsection{Practical Implications}

From a managerial perspective, this research guides managers in buyer organizations on how to employ knowledge-sending roles to develop supply chain competence. Our results show that taking up an extreme position on the continuum from dominant knowledge-receiver to dominant knowledge-sender can be counter-productive. Thus, an intermediate position or moving towards a moderately intensive knowledge-sending role is advisable. The potential benefits of this can be leveraged if buyer organizations develop both internal desorptive and absorptive capacities and adjust them to the external absorptive and desorptive capacities of the members of their supply network once they have understood them. Further, the findings provide insights to managers on when it is appropriate to invest in desorptive and absorptive capabilities under asymmetric supply chain knowledge transfer. Consequently, we suggest identifying the magnitude of desorptive and absorptive capabilities across all parties involved in knowledge transfer.

Likewise, our results encourage managers to focus on mutual teaching (and learning) to benefit the entire supply chain. This creates transparency that benefits the buyer organization as well as the suppliers in operating terms, enhancing their competence for managing the supply chain with direct implications for customers. Likewise, managers can use this knowledge to shift from a greatly asymmetric knowledge transfer position to a more symmetric one to improve supply chain competence.

Taken together, these considerations enable the buyer organization to explore and better prepare both itself and the members of its supply network for achieving successful knowledge transfer outcomes.

\subsection{Limitations and Future Research Directions}

As in any study, our research has limitations that we now acknowledge. First, we used a single informant per surveyed organization instead of surveying all members involved in knowledge transfer. Although we confirmed common method variance was not a problem, future studies could further minimize this risk by increasing the number of informants. Second, evaluations of the desorptive and absorptive capacities of other members of the network were based on the perceptions of the buyer organization. Future research could therefore look to incorporate responses from other network participants. Third, our data is cross-sectional yet dynamic capabilities evolve over time. This work should therefore be 
complemented in the future by longitudinal analysis. Qualitative case studies should also be conducted to further unpack how to achieve and maintain desorptive capacity fit in a supply chain context. Further research should also be performed in a wider range of industrial and geographical settings. In addition, testing the effect of power on performance in asymmetrical knowledge transfer would be interesting. Likewise, testing the characteristics of the knowledge being transferred could be considered. Finally, future research could extend analysis of the senders and recipients of knowledge to others fields of management.

\section{References}

Aiken, L.S., and S.G. West. 1991. Multiple regression: Testing and interpreting interaction. Thousand Oaks: Sage Publications.

Argote, L., and E. Darr. 2000. "Repositories of knowledge in franchise organizations: Individual, structural and technological." The Nature and Dynamics of Organizational Capabilities 82 (1): 5165.

Armstrong, J.S., and T.S. Overton. 1977. "Estimating nonresponse bias in mail surveys." Journal of Marketing Research 14 (3): 396-402.

Azadegan, A. 2011. "Benefiting from supplier operational innovativeness: The influence of supplier evaluations and absorptive capacity.” Journal of Supply Chain Management 47 (2): 49-64.

Barney, J.B. 2012. "Purchasing, supply chain management and sustained competitive advantage: The relevance of resource-based theory." Journal of Supply Chain Management 48 (2): 3-6.

Braun, A., E. Mueller, and S. Adelhelm. 2012. "Knowledge flow at the fuzzy front-end of inter-firm R\&D collaborations - Insights into SMEs in the pharmaceutical industry." International Journal of Entrepreneurship and Innovation Management 15 (1/2): 29-46.

Cao, M., and Q. Zhang. 2011. "Supply Chain Collaboration: Impact on Collaborative Advantage and Firm Performance." Journal of Operations Management 29: 163-180. doi:10.1016/j.jom.2010.12.008.

Cassiman, B., and R. Veugelers. 2006. "In search of complementarity in innovation strategy: internal R\&D and external knowledge acquisition." Management Science 52: 68-82.

Cohen, W.M., and D.A. Levinthal. 1990. "Absorptive Capacity: A New Perspective on Learning and Innovation." Administrative Science Quarterly 35 (1): 128-152.

Cohen, J., P. Cohen, S.G. West, and L.S. Aiken. 2003. Applied multiple regression and correlation for the behavioral sciences. $3^{\text {rd }}$ ed. Mahwah, NJ: Lawrence Erlbaum Associates.

Chang, S.J., V. Witteloostuijn, and L. Eden. 2010. "From the editors: Common method variance in international business research.” Journal of International Business Studies 41 (2): 178-184. 
Chang, Y.Y., Y. Gong, and M.W. Peng. 2012. "Expatriate Knowledge Transfer, Subsidiary Absorptive Capacity and Subsidiary Performance.” Academy of Management Journal 55 (4): 927948.

Cheng, J-H., and K-L. Lu. 2017. "Enhancing effects of supply chain resilience: Insights from trajectory and resource-based perspectives." Supply Chain Management: An International Journal 22 (4): 329-340.

Choi, T.Y., and D.R. Krause. 2006. "The supply base and its complexity: implications for transaction costs, risks, responsiveness, and innovation.” Journal of Operations Management 24 (5): 637-652.

Chow, W.S., C.N. Madu, C.H. Kuei, M.H. Lu, C. Lin, and H. Tseng. 2008. "Supply chain management in the US and Taiwan: An empirical study." Omega 36: 665-679.

Denford, J.S., and A. Feriss. 2018. "Absorption, combination and desorption: knowledge-oriented boundary spanning capabilities." Journal of Knowledge Management 22 (7): 1425-1441.

Derwik, P., and D. Hellström. 2017. "Competence in supply chain management: a systematic review." Supply Chain Management: An International Journal 22 (2): 200-218.

Dezi, L., V. Cillo, A. Usai, and P. Pisano. 2018. "Equity crowdfunding in technology transfer strategies and licensing." International Journal of Technology Management 78 (1-2): 28-51.

Dyer, J.H., and H. Singh. 1998. "The relational view: Cooperative strategy and sources of interorganizational competitive advantage." Academy of Management Review 23 (4): 660-679.

D'Souza, D.E., and S.S. Kulkarni. 2015. "A framework and model for absorptive capacity in a dynamic multi-firm environment." International Journal of Production Economics 167: 50-62.

Easterby-Smith, M., M. Lyles, and E. Tsang. 2008. "Inter-Organizational Knowledge Transfer: Current Themes and Future Prospects." Journal of Management Studies 45: 677-690. doi:10.1111/j.1467-6486.2008.00773.x.

Fornell, C., and D.F. Larcker. 1981. "Evaluating structural equation models with unobservable variables and measurement error." Journal of Marketing Research 18: 39-50.

Green, Jr., W. Kenneth, R. Anthony Inman, L.M. Birou, and D. Whitten. 2014. "Total JIT (TJIT) and its impact on supply chain competency and organizational performance." International Journal of Production Economics 147: 125-135.

Gupta, A. K., and V. Govindarajan. 2000. "Knowledge flows within multinational corporations." Strategic Management Journal 21: 473-496.

Hair, J., R. Tatham, R. Anderson, and W. Black. 2010. Multivariate Data Analysis. Upper Saddle River, NJ: Prentice-Hall.

Handfield, R.B., P.D. Cousins, B. Lawson, and K.J. Peterson. 2015. "How can supply management really improve performance? A knowledge-based model of alignment capabilities." Journal of Supply Chain Management 51 (3): 3-17.

Handoko, I., M. Bresnen, and Y. Nugroho. 2018. "Knowledge exchange and social capital in supply chains." International Journal of Operations and Production Management 38 (1): 90-108. 
Hosseini, S., A. Kees, J. Manderscheid, M. Röglinger, and M. Rosemann. 2017. "What does it take to implement open innovation? Towards an integrated capability framework." Business Process Management Journal 23 (1): 87-107.

Huang, F., and J. Rice. 2009. "The role of absorptive capacity in facilitating "open innovation" outcomes: a study of Australian SMES in the manufacturing sector." International Journal of Innovation Management 13 (2): 201-220.

Ishihara, H., and J. Zolkiewski. 2017. "Effective knowledge transfer between the headquarters and a subsidiary in a MNC: the need for heeding capacity." Journal of Business and Industrial Marketing 32 (6): 813-824.

Ketchen, D. J., K.D. Wowak, and C.W. Craighead. 2014. "Resource Gaps and Resource Orchestration Shortfalls in Supply Chain Management: The Case of Product Recalls." Journal of Supply Chain Management 50 (3): 6-15. doi:10.1111/jscm.12047.

Lane, P. J., and M. Lubatkin. 1998. "Relative absorptive capacity and interorganizational learning." Strategic Management Journal 19: 461-477.

Lichtenthaler, U., and E. Lichtenthaler. 2009. "A capability-based framework for open innovation: Complementing absorptive capacity.” Journal of Management Studies 46 (8): 1315-1338.

Lichtenthaler, U., and E. Lichtenthaler. 2010. "Technology transfer across organizational boundaries: Absorptive capacity and desorptive capacity." California Management Review 53 (1): 154-170.

Luo, X., and L. Deng. 2009. "Do Birds of a Feather Flock Higher? The Effects of Partner Similarity on Innovation in Strategic Alliances in Knowledge Intensive Industries." Journal of Management Studies 46: 1005-1030. doi:10.1111/j.1467-6486.2009.00842.x

Malhotra, M.K., and A.W. Mackelprang. 2012. "Are internal manufacturing and external supply chain flexibilities complementary capabilities?.” Journal of Operations Management 30: 180-200.

Martín de Castro, G. 2015. "Knowledge management and innovation in knowledge-based and hightech industrial markets: The role of openness and absorptive capacity." Industrial Marketing Management 47: 143-146.

Meinlschmidt, J., K. Foerstl, and H.F. Kirchoff. 2016. "The role of absorptive and desorptive capacity in sustainable supply management." International Journal of Physical Distribution \& Logistics Management 26 (2): 117-211.

Moedas, C.A., and S.B. Mahmoud-Jouini. 2008. "Absorptive capacity and source-recipient complementarity in designing new products: An empirically derived framework." Journal of Product Innovation Management, 25: 473-490.

Moorman, C., and R.J. Slotegraaf. 1999. "The Contingency Value of Complementary Capabilities in Product Development.” Journal of Marketing Research 36: 239-257.

Mowery, D., J. Oxley, and B. Silverman. 1996. "Strategic Alliances and Interfirm Knowledge Transfer.” Strategic Management Journal 17 (2): 77-91. doi:10.1002/smj.4250171108. 
Mowery, D.C., J. Oxley, and B. Silverman. 1998. "Technological overlap and interfirm cooperation: implications for the resource-based view of the firm." Research Policy 27 (5): 507-523.

Mu, J., F. Tang, and D. Maclachlan. 2010. "Absorptive and disseminative capacity: Knowledge transfer in intra-organization networks." Expert Systems and Applications 37: 31-38. 10.1016/j.eswa.2009.05.019.

Müller-Seitz, G. 2012. "Absorptive and desorptive capacity-related practices at the network level - the case of SEMATECH.” R\&D Management 42 (1): 90-99.

Nunnally, J.C., and I.H. Bernstein.1994. Psychometric Theory, New York: McGraw-Hill.

Nyaga, G.N., D.F. Lynch, D. Marshall and E. Ambrose. 2013. "Power asymmetry, adaptation and collaboration in dyadic relationships: involving a powerful partner." Journal of Supply Chain Management 49 (3): 42-65.

Olson, D.L. 2018. "View of IJPR contributions to knowledge management in supply chains." International Journal of Production Research 56 (1-2): 733-742. doi: 10.1080/00207543.2017.1398427.

Patel, P.C., S. Terjsen, and D. Li. 2012. "Enhancing effects of manufacturing flexibility through operational absorptive capacity and operational ambidexterity." Journal of Operations Management 30: 201-220.

Peng, G., D. Dey, and A. Lahiri. 2014. "Healthcare IT adoption: An analysis of knowledge transfer in socioeconomic networks.” Journal of Management Information Systems 31 (3): 7-34.

Pérez Salazar M.R., A.A. Aguilar Lasserre., M.G. Cedillo-Campos., U. Juárez Martínez, and R. Posada Gómez. 2018. "Processes and measurement of knowledge management in supply chains: an integrative systematic literature review." International Journal of Production Research. 1-24.

Podsakoff, P. M., S. B. MacKenzie, J-Y. Lee, and N. P. Podsakoff. 2003. "Common method biases in behavioral research: A critical review of the literature and recommended remedies." Journal of Applied Psychology 88: 879-903.

Pulles, N.J., J. Veldman., H. Schiele, and H. Sierksma. 2014. "Pressure or pamper? The effects of power and trust dimensions on supplier resource allocation." Journal of Supply Chain Management 50 (3): 16-36.

Revilla, E., M.J. Sáenz, and D. Knoppen. 2013. "Towards an empirical typology of buyer-supplier relationships based on absorptive capacity." International Journal of Production Research 51 (10): 2935-2951.

Richey, R.G., P.J. Daugherty, and A.S. Roath. 2007. "Firm technological readiness and complementarity: Capabilities impacting logistics service competency and performance.” Journal of Business Logistics 28 (1): 195-228.

Roldán Bravo, M.I., A. Ruiz Moreno, and F.J. Lloréns Montes. 2016. "Supply network-enabled innovations: An analysis based on dependence and complementarity of capabilities." Supply Chain Management: An International Journal 21 (5): 642-660. 
Roldán Bravo, M.I., A. Ruiz Moreno, and F.J. Lloréns Montes. 2018. "Examining desorptive capacity in supply chains: the role of organizational ambidexterity." International Journal of Operations \& Production Management 38 (4): 534-553.

Ruiz Moreno, A., M.C. Haro Domínguez., I. Tamayo Torres, and T. Ortega Egea. 2016. "Quality management and administrative innovation as firms'capacity to adapt to their environment." Total Quality Management 27 (1): 48-63.

Sáenz, M.J., E. Revilla, and D. Knoppen. 2014. “Absorptive capacity in buyer-supplier relationships: Empirical evidence of its mediating role." Journal of Supply Chain Management 50 (2): 18-40.

Saris, W.E., A, Satorra, A. and W.M. Van der Veld. 2009. "Testing structural equation models or detection of misspecifications?" Struct. Equ. Model.: A Multidisciplinary Journal 16: 561-582.

Schulze, A., G. Brojerdi, and G. Von Krogh. 2014. "Those who know, do. Those who understand, teach: Disseminative capability and knowledge transfer in the automotive industry." Journal of Product Innovation Management 31 (1): 79-97.

Shashi., P. Centobelli, R. Cerchione, and R. Singha. 2019. "The impact of leanness and innovativeness on environmental and financial performance: Insights from Indian SMEs." International Journal of Production Economics 212: 111-124.

Sikimic, U., V. Chiesa., F. Frattini, and V.G. Scalera. 2016. "Investigating the influence of technology inflows on technology outflows in open innovation processes: a longitudinal analysis." Journal of Product Innovation Management 33 (6): 652-669.

Soda, G., and M. Furlotti. 2017. "Bringing tasks back in: An organizational theory of resource complementarity and partner selection." Journal of Management 43 (2): 348-375.

Spithoven, A., B. Clarysse, and M. Knockaert. 2010. "Building absorptive capacity to organize inbound open innovation in traditional industries." Technovation 30 (1): 10-21.

Szász, L., B-G. Rácz, M. Scherrer, and P. Deflorin. 2019. "Disseminative capabilities and manufacturing plant roles in the knowledge network of MNCs." International Journal of Production Economics 208: 294-304.

Takeishi, A. 2002. "Knowledge Partitioning in the Interfirm Division of Labor: The Case of Automotive Product Development." Organization Science 13 (3): 321-338. 10.1287/orsc.13.3.321.2779.

Teece, D. J., G.P. Pisano, and A. Shuen. 1997. "Dynamic Capabilities and Strategic Management." Strategic Management Journal 18 (7): 509-533.

Teece, D.J. 2007. "Explicating dynamic capabilities: The nature and microfoundations of (sustainable) enterprise performance.” Strategic Management Journal 28 (13): 1319-1350.

Terpend, R., and B. Ashenbaum. 2012. "The Intersection of Power, Trust and Supplier Network Size: Implications for Supplier Performance.” Journal of Supply Chain Management 48: 52-77. 
Vanhaverbeke, W., M. Cloodt, and V. Van de Vrande. 2007. "Connecting absorptive capacity and open innovation." In Proceedings of the CAS Workshop on Innovation in CAS Centre for Advanced Study, 1-22.

Volberda, H.W., N.J. Foss, and M.A. Lyles. 2010. "Absorbing the concept of absorptive capacity: How to realize its potential in the organization field." Organization Science 21 (4): 931-951.

Wagner, S.M. 2012. “Tapping supplier innovation.” Journal of Supply Chain Management 48 (2): 3752.

Wang, C.L., and P.K. Ahmed. 2007. "Dynamic capabilities: A review and research agenda." International Journal of Management Reviews 9 (1): 31-51.

White, R.E., J.N. Pearson, and J.R. Wilson. 1999. "JIT manufacturing: a survey of implementations in small and large US manufacturers." Management Science 45 (1): 1-15.

Whitehead, K.K., Z.G. Zacharia, and E.L. Prater. 2016. "Absorptive capacity versus distributive capability: The asymmetry of knowledge transfer." International Journal of Operations \& Production Management 36 (10): 1308-1332.

Whitehead, K., Z. Zacharia, and E. Prater. 2019. "Investigating the role of knowledge transfer in supply chain collaboration." International Journal of Logistics Management 30 (1): 284-302.

Wu, I.L., C.H. Chuang, and C.H. Hsu. 2014. "Information sharing and collaborative behaviors in enabling supply chain performance: a social exchange perspective." International Journal of Production Economics 148: 122-132.

Yang, S.-M., S.-C. Fang., S.-R. Fang, and C.-H. Chou. 2014. "Knowledge exchange and knowledge protection in interorganizational learning: The ambidexterity perspective." Industrial Marketing Management 43 (2): 346-358.

Zahra, S.A., and G. George. 2002. "Absorptive capacity: A review, reconceptualization, and extension." Academy of Management Review 27 (2): 185-203.

Ziegler, N., F. Ruether., M. Bader, and O. Gassmann. 2013. "Creating value through external intellectual property commercialization: A desorptive capacity view." Journal of Technology Transfer 38: 930-949. 


\section{Appendix 1: Measurement Scales and Items}

Buyer's Desorptive Capacity (Roldán Bravo et al. 2016; $\alpha=0.916$ )

DC1. We are able to identify relevant knowledge from our organization to our supply network and transfer it.

DC2. The transfer of knowledge to our supply network is well organized.

DC3. Our organization supports the knowledge transfer process to our supply network enough.

Supply Network's Desorptive Capacity (Roldán Bravo et al. 2016; $\alpha=0.88$ )

DC4. Our supply network is able to identify relevant knowledge to our organization and transfer it.

DC5. The transfer of knowledge from our supply network is well organized.

DC6. Our supply network supports the knowledge transfer process to our organization enough.

Supply Chain Competence (Chow et al. 2008; $\alpha=0.919$ )

SCC1. Our ability to respond to request in a timely manner is excellent

SCC2. Our ability in filling orders with improved accuracy is excellent.

SCC3. Our ability to make high-quality products and services is excellent.

SCC4. Our ability to respond to the needs of key customers and with key suppliers is excellent.

SCC5. Our ability in managing supply chain inventory is excellent.

SCC6. Our ability to meet promised delivery date is excellent.

SCC7. Our ability to predict sales is excellent, with increasing precision each time.*

SCC8. Our ability to issue advanced notice on shipping delays is excellent.

SCC9. Our ability to enhance supply chain's position in terms of integrity is excellent.

Buyer's Absorptive Capacity (Wagner 2012; $\alpha=0.86$ )

AC1. We are able to identify and use relevant knowledge from our supply network.*

AC2. We have adequate routines to analyse external knowledge from this supply network.

AC3. We can successfully combine new knowledge obtained from this supply network with existing knowledge.

AC4. We can successfully exploit the new knowledge in concrete applications.

Supply Network's Absorptive Capacity (Wagner 2012; $\alpha=0.88$ )

AC5. Our supply network is able to identify and use relevant knowledge from us.*

AC6. Our supply network has adequate routines to analyse external knowledge from us.

AC7. Our supply network successfully combines new knowledge obtained from us with existing knowledge.

AC8. Our supply network can successfully exploit the new knowledge in concrete applications.

*Items were removed due to low factor loadings. 
Figure 1. Summary of Hypothesized Relationships

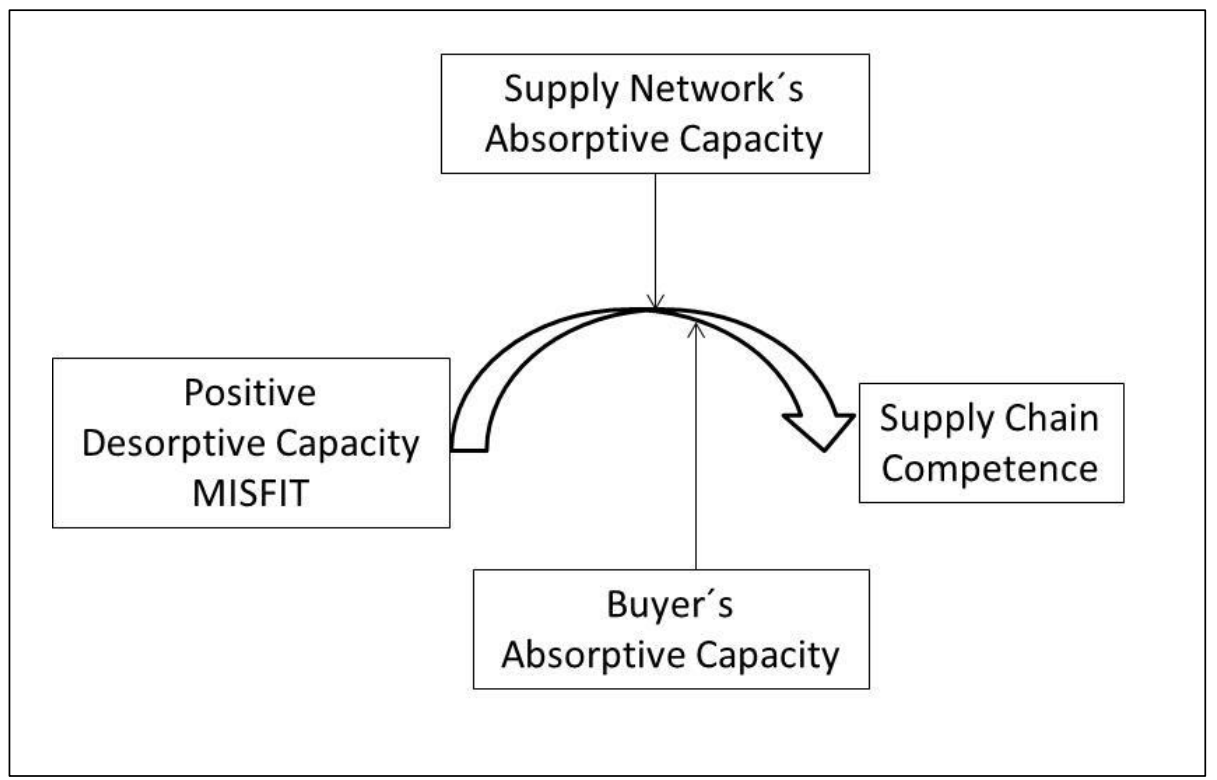

Figure 2. Relationship between Positive Desorptive Capacity Misfit and Supply Chain Competence

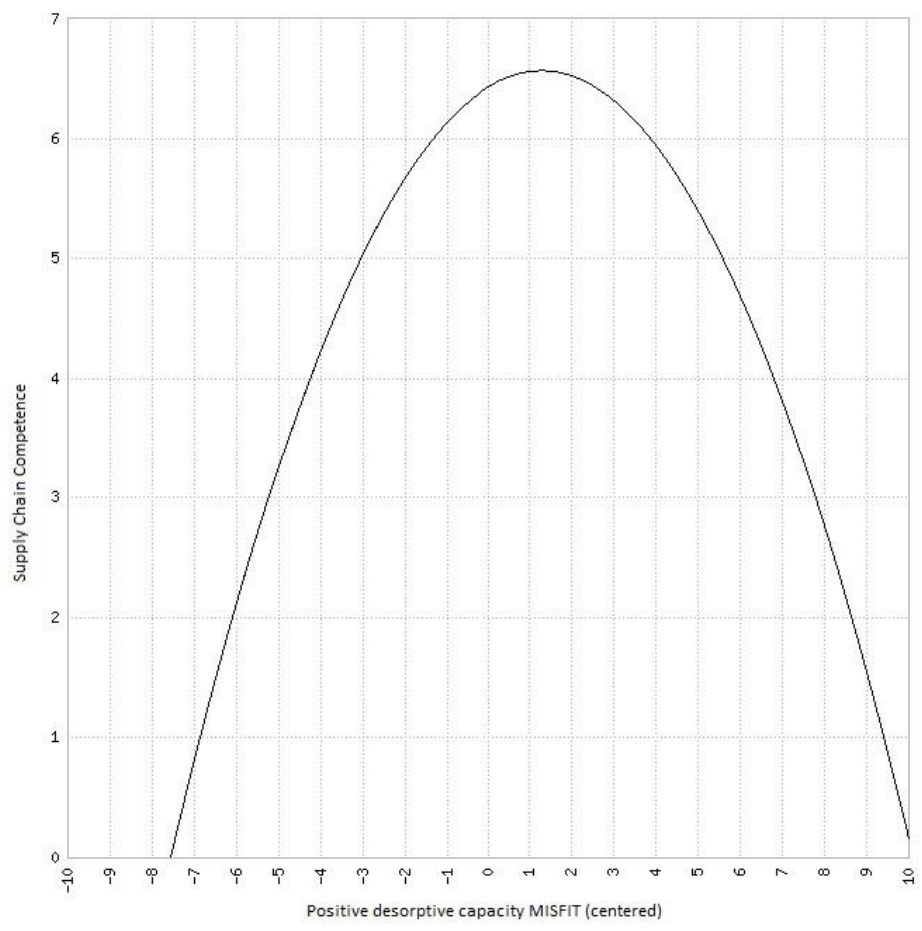


Figure 3. Relationship between Positive Desorptive Capacity Misfit and Supply Chain Competence as a Function of the Supply Network's (SN's) Absorptive Capacity

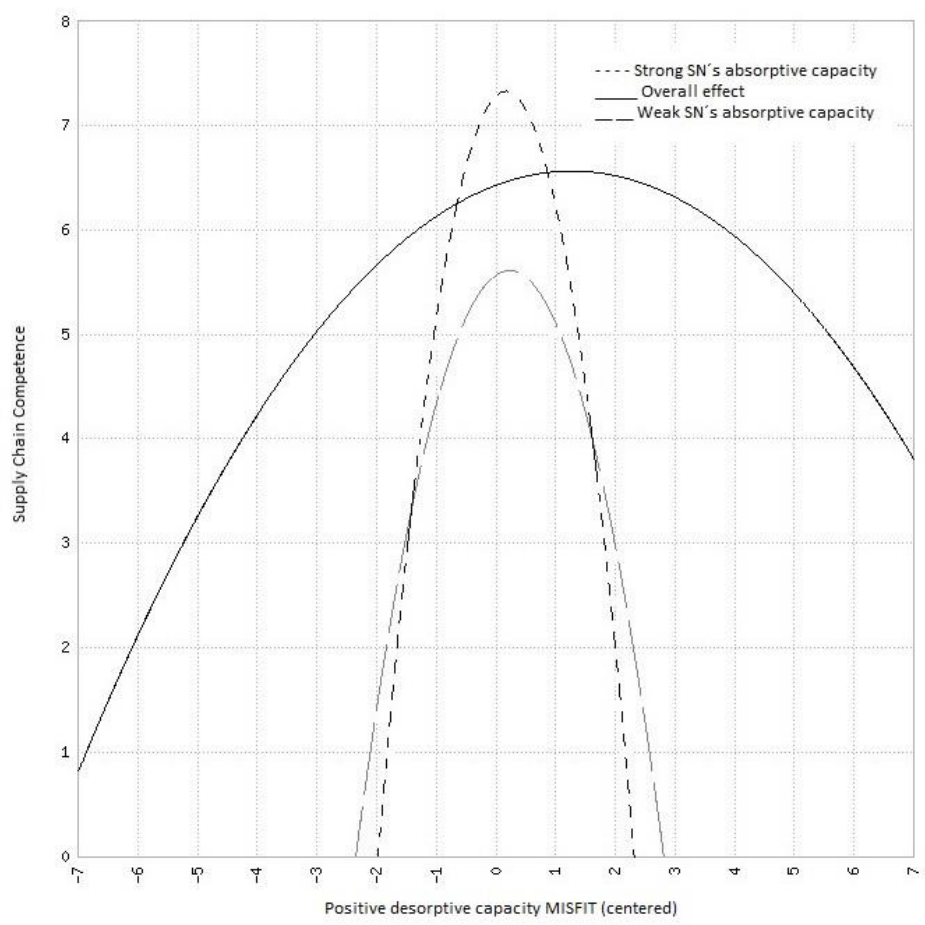


Table 1. Sample Demographics

\begin{tabular}{|c|c|c|}
\hline Characteristics & Frequency & Percent \\
\hline \multicolumn{3}{|l|}{ Industry type } \\
\hline High-tech Manufacturing & 75 & 30 \\
\hline Computer & 9 & 3.6 \\
\hline Chemistry and pharmaceuticals & 33 & 13.2 \\
\hline Machinery and equipment & 11 & 4.4 \\
\hline Motor vehicles and transport equipment & 22 & 8.8 \\
\hline Traditional Manufacturing & 89 & 35.6 \\
\hline Textiles & 12 & 4,8 \\
\hline Paper & 9 & 3.6 \\
\hline Graphic arts & 25 & 10 \\
\hline Plastic & 34 & 13.6 \\
\hline Furniture & 9 & 3.6 \\
\hline Services & 86 & 34.4 \\
\hline Communications/high tech & 22 & 8.8 \\
\hline Other services & 64 & 25.6 \\
\hline \multicolumn{3}{|l|}{ Annual revenue (€) } \\
\hline $1000-10,000 \mathrm{M}$ & 81 & 32.4 \\
\hline $10,000-100,000 \mathrm{M}$ & 149 & 59.6 \\
\hline $100,000 \mathrm{M}$ & 20 & 8 \\
\hline \multicolumn{3}{|l|}{ Number of employees } \\
\hline $0-49$ & 13 & 5.2 \\
\hline $50-250$ & 195 & 78 \\
\hline $250-1000$ & 42 & 16.8 \\
\hline \multicolumn{3}{|l|}{ Number of suppliers } \\
\hline$<100$ & 210 & 84 \\
\hline $100-300$ & 36 & 14.4 \\
\hline$>300$ & 4 & 1.6 \\
\hline \multicolumn{3}{|l|}{ Firm age } \\
\hline$<10$ & 69 & 27.6 \\
\hline $10-25$ & 164 & 65.6 \\
\hline$>25$ & 17 & 6.8 \\
\hline
\end{tabular}


Table 2. Measurement Model Results

\begin{tabular}{|c|c|c|c|c|c|}
\hline Variables & Indicators & $\begin{array}{c}\text { Standardised } \\
\text { Factor Loadings }\end{array}$ & AVE & $\mathbf{C R}$ & CITC \\
\hline \multirow{3}{*}{$\begin{array}{c}\text { Buyer's Desorptive } \\
\text { Capacity }\end{array}$} & DC1 & 0.828 & \multirow{3}{*}{0.7909} & \multirow{3}{*}{0.919} & \multirow{3}{*}{$0.78-0.88$} \\
\hline & DC2 & 0.946 & & & \\
\hline & DC3 & 0.89 & & & \\
\hline \multirow{3}{*}{ SN’s Desorptive Capacity } & DC4 & 0.784 & \multirow{3}{*}{0.7167} & \multirow{3}{*}{0.883} & \multirow{3}{*}{$0.71-0.82$} \\
\hline & DC5 & 0.893 & & & \\
\hline & DC6 & 0.859 & & & \\
\hline \multirow{8}{*}{ Supply Chain Competence } & SCC1 & 0.749 & \multirow{8}{*}{0.5943} & \multirow{8}{*}{0.921} & \multirow{8}{*}{$0.68-0.8$} \\
\hline & SCC2 & 0.833 & & & \\
\hline & SCC3 & 0.72 & & & \\
\hline & SCC4 & 0.751 & & & \\
\hline & SCC5 & 0.71 & & & \\
\hline & SCC6 & 0.834 & & & \\
\hline & SCC8 & 0.758 & & & \\
\hline & SCC9 & 0.802 & & & \\
\hline \multirow{3}{*}{$\begin{array}{c}\text { Buyer's Absorptive } \\
\text { Capacity }\end{array}$} & $\mathrm{AC} 2$ & 0.71 & \multirow{3}{*}{0.7021} & \multirow{3}{*}{0.875} & \multirow{3}{*}{$0.64-0.8$} \\
\hline & $\mathrm{AC} 3$ & 0.904 & & & \\
\hline & $\mathrm{AC4}$ & 0.886 & & & \\
\hline \multirow{3}{*}{$\begin{array}{l}\text { SN’s Absorptive } \\
\text { Capacity }\end{array}$} & AC6 & 0.815 & \multirow{3}{*}{0.7246} & \multirow{3}{*}{0.887} & \multirow{3}{*}{$0.73-0.84$} \\
\hline & AC7 & 0.905 & & & \\
\hline & AC8 & 0.831 & & & \\
\hline
\end{tabular}


Table 3. Correlation Matrix and Descriptive Statistics $(N=250)$

\begin{tabular}{|c|c|c|c|c|c|c|c|c|c|c|c|}
\hline Variable & Mean & S.D. & 1 & 2 & 3 & 4 & 5 & 6 & 7 & 8 & 9 \\
\hline 1.Age & 2.43 & 0.67 & & & & & & & & & \\
\hline 2.Employees (n) & 4.85 & 0.69 & -0.087 & & & & & & & & \\
\hline 3.Suppliers & 2.94 & 1.32 & 0.1 & 0.082 & & & & & & & \\
\hline 5.Firm's DC & 5.26 & 0.99 & 0.045 & -0.095 & 0.063 & 0.024 & & & & & \\
\hline 6.SN's DC & 5.21 & 0.92 & 0.115 & -0.11 & 0.022 & 0.068 & $0.679^{* * *}$ & & & & \\
\hline 9.SN's AC & 5.0 & 0.86 & $0.126^{* *}$ & -0.057 & -0.02 & 0.077 & $0.492^{* * *}$ & $0.579^{* * *}$ & -0.06 & $0.645^{* * *}$ & \\
\hline 10.SC Competence & 5.86 & 0.76 & $0.124^{* *}$ & $-0.132^{* *}$ & -0.014 & 0.036 & $0.63^{* * *}$ & $0.493^{* * * *}$ & $0.221^{* * *}$ & $0.574^{* * *}$ & $0.435^{* * *}$ \\
\hline
\end{tabular}

Note: DC (Desorptive Capacity); AC (Absorptive Capacity); **p<0.05; ***p<0.01. 
Table 4. Results of the Hierarchical Linear Modeling-Based Regression Analysis

\begin{tabular}{|c|c|c|c|c|c|c|c|c|c|}
\hline & Model 1 & Model 2 & Model 3 & Model 4 & Model 5 & Model 6 & Model 7 & Model 8 & Model 9 \\
\hline Age & $0.12^{*}$ & $0.138^{* *}$ & $0.132^{* *}$ & 0.075 & 0.085 & 0.071 & 0.085 & 0.069 & 0.081 \\
\hline Employees (n) & $-0.128^{* *}$ & $-0.125^{*}$ & $-0.145^{* *}$ & $-0.122^{* *}$ & $-0.125^{* *}$ & $-0.129^{* *}$ & $-0.125^{* *}$ & $-0.129^{* *}$ & $-0.106^{* * *}$ \\
\hline Suppliers & -0.017 & -0.031 & -0.043 & -0.041 & -0.03 & -0.036 & -0.03 & -0.036 & -0.029 \\
\hline Sector & -.025 & -0.016 & -0.042 & -0.054 & -0.052 & -0.054 & -0.053 & -0.054 & -0.022 \\
\hline Positive DC Misfit & & $0.234^{* * *}$ & $0.216^{* * *}$ & $0.153^{* * *}$ & $0.241^{* * *}$ & $0.132^{* *}$ & $0.241^{* * *}$ & $0.122^{* *}$ & $0.241^{* * *}$ \\
\hline Positive DC Misfit Squared & & & $-0.151^{* *}$ & $-0.098^{* * * *}$ & $-0.109^{*}$ & -0.023 & $-0.109^{*}$ & -0.013 & $-0.167^{* * *}$ \\
\hline Firm's AC & & & & $0.534^{* * *}$ & & $0.534^{* * *}$ & & $0.524^{* * *}$ & \\
\hline SN's AC & & & & & $0.425^{* * *}$ & & $0.425^{* * *}$ & & $0.556^{* * *}$ \\
\hline Positive DC MisFit x AC & & & & & & $-0.145^{* *}$ & & $-0.14^{* *}$ & \\
\hline Positive DC MisFit x SN AC & & & & & & & -0.001 & & 0.038 \\
\hline Positive DC MisFit Squared x AC & & & & & & & & 0.032 & \\
\hline Positive DC MisFit Squared x SN AC & & & & & & & & & $-0.262^{* * *}$ \\
\hline $\mathrm{R}^{2}$ & 0.031 & 0.085 & 0.107 & 0.38 & 0.281 & 0.395 & 0.281 & 0.395 & 0.324 \\
\hline Adjusted $\mathrm{R}^{2}$ & 0.015 & 0.067 & 0.085 & 0.362 & 0.261 & 0.375 & 0.258 & 0.373 & 0.299 \\
\hline Change in $\mathrm{R}^{2}$ & $0.031^{*}$ & $0.054^{* * *}$ & $0.021^{* *}$ & $0.274^{* * *}$ & $0.175^{* * *}$ & $0.014^{* *}$ & 0 & 0.001 & $0.043^{* * *}$ \\
\hline
\end{tabular}

Note: DC (Desorptive Capacity); AC (Absorptive Capacity); ${ }^{*} \mathrm{p}<0.1 ; * * \mathrm{p}<0.05 ; * * * \mathrm{p}<0.01$. 
Table 5. Results of the Post-hoc Analysis

\begin{tabular}{|c|c|c|c|}
\hline & Model 1 & Model 2 & Model 3 \\
\hline Age & $0.12^{*}$ & $0.14^{* *}$ & $0.132^{* *}$ \\
\hline Employees (n) & $-0.128^{* *}$ & $-0.107^{*}$ & $-0.125^{* *}$ \\
\hline Suppliers & -0.017 & -0.043 & -0.053 \\
\hline Sector & -.025 & -0.012 & -0.038 \\
\hline Positive DC-AC Misfit & & $0.272^{* * *}$ & $0.279^{* * *}$ \\
\hline Positive DC-AC Misfit Squared & & & $-0.151^{* *}$ \\
\hline $\mathrm{R}^{2}$ & 0.031 & 0.104 & 0.126 \\
\hline Adjusted $\mathrm{R}^{2}$ & 0.015 & 0.085 & 0.104 \\
\hline Change in $\mathrm{R}^{2}$ & $0.031^{*}$ & $0.072^{* * *}$ & $0.022^{* *}$ \\
\hline
\end{tabular}

Note: DC (Desorptive Capacity); AC (Absorptive Capacity); *p $<0.1 ; * * p<0.05$; $* * * \mathrm{p}<0.01$. 